\title{
A postpartum woman with icterus: A case of G6PD deficiency in a female
}

\author{
Sandakumari GVN ${ }^{1}$, MendisV ${ }^{2}$, Weerawansa MRP ${ }^{1}$, Pilapitiya SD ${ }^{1}$, Dahanayake $\mathrm{NJ}^{1}$, Siribaddana $\mathrm{SH}^{1}$ \\ ${ }^{\prime}$ Department of Medicine, ${ }^{2}$ Department of Pathology, Faculty of Medicine and Allied Sciences, Rajarata \\ University of Sri Lanka, Saliyapura, Sri Lanka.
}

Correspondence: $\quad$ Dr. G.V.N. Sandakumari

Department of Medicine, Faculty of Medicine and Allied Sciences, Rajarata University of Sri Lanka, Saliyapura, Sri Lanka.

e-mail: sandakumari82@gmail.com

\section{Introduction}

G6PD deficiency is an X-linked recessive hereditary disease. G6PD is involved in the production of NADPH which is important in the prevention of oxidative damage of red blood cells (1). Since it is an $\mathrm{X}$-linked disorder the clinical manifestations should be seen almost exclusively in males. However, heterozygous females will also be affected if there is an inactivation of normal $\mathrm{X}$ chromosome which is an unfavourable lyonization.

We present a case report of a 28 -year old woman with G6PD deficiency, most likely due to random inactivation of normal $\mathrm{X}$ chromosome.

\section{Case report}

A 28-year-old woman in her second twin pregnancy at a period of amenorrhea (POA) of 36 weeks was admitted with three day history of fever, lower abdominal pain and dysuria. She was started on nitrofurantoin $100 \mathrm{mg}$ six hourly to cover a possible urinary tract infection. During her stay at ward she had labour pains and an emergency caesarean section was done due to the indication of twin in labour. Two days after caesarean section she developed yellowish discolouration of her eyes. There was no change in the colour of urine or stools and she did not complain of pruritus.

Her past medical history was unremarkable other than for previous caesarean section two years back. She gave no history of neonatal jaundice, foreign travel or family history of anaemia or jaundice.
Examination was unremarkable except for mild icterus and conjunctival pallor.

Investigations revealed anaemia with haemoglobin of $7.3 \mathrm{~g} / \mathrm{dL}$ and indirect hyperbilirubinaemia. Her reticulocyte count was $6 \%$ and LDH was $1911 \mathrm{U} / \mathrm{L}$ suggestive of an ongoing haemolytic process. Blood picture showed many bite cells, blister cells, fragmented cells and numerous polychromatic cells suggesting the possibility of underlying G6PD deficiency (Figure). In order to confirm the diagnosis sample of blood from patient's father was assessed for G6PD level and it was $0.40 \mathrm{U} / \mathrm{g} \mathrm{Hb}(4.6$ - 13.50). G6PD level of the patient was assessed three months later and it was found to be only $2.50 \mathrm{U} / \mathrm{gHb}$. Genetic studies were not done.

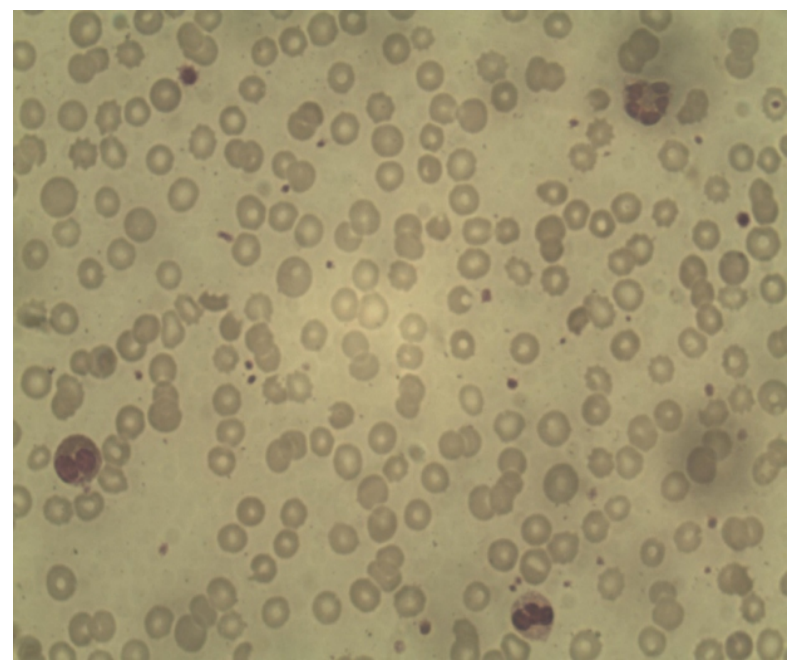

Figure: Blood film of the patient showing bite cells, fragmented cells, numerous polychromatic cells, few blister cells and spherocytes (probably transfused cells) 
She was transfused one pint of blood and managed with folic acid $5 \mathrm{mg}$ daily. Dietary advice was given to avoid antioxidants.

Haemolysis in our patient was most probably triggered by nitrofurantoin given as a treatment for her urinary tract infection.

\section{Discussion}

G6PD deficiency is a X-linked recessive hereditary disease in which abnormally low levels of glucose6-phosphate dehydrogenase (G6PD) occurs $(1,2)$. It is the commonest enzyme deficiency seen worldwide (4).

G6PD is an enzyme in the pentose phosphate pathway. It is involved in the production of NADPH which maintains glutathione in reduced state when erythrocytes are subjected to an oxidant stress $(1,2)$.

The disease is highly prevalent in Africa, southern Europe, the Middle East, South East Asia, and Oceania and in descendants of migrants from these areas (1). Approximately 400 million people are affected worldwide (4). Reduced concentrations of G6PD render red blood cells susceptible to haemolysis under conditions that occur when oxidant drugs are administered, when fava beans are ingested (favism), or during infection (1).

Most individuals who are G6PD deficient remain clinically asymptomatic (2). However, they are at risk of developing acute haemolytic anaemia in response to triggers. In most cases the haemolytic attack is self limiting but in rare instances it can be severe enough needing blood transfusions (4). Depending on the number of red blood cells that have been destroyed, the haemoglobin concentration returns to normal in three to six weeks (2).

Since G6PD deficiency is an X-linked disorder, the main clinical manifestations are seen in hemizygous males (2). The situation in females is complex. Many heterozygote females with G6PD deficiency have red cell G6PD levels which are approximately 50\% of normal (3). Human female is a genetic mosaic containing cells with genetically active maternal $\mathrm{X}$-chromosome and cells with genetically active paternal X-chromosome; fixation of the role of each chromosome is determined at an early stage of embryonic development (3). Female patients heterozygous for G6PD deficiency have two cell populations one with a normal enzyme content and one deficient in enzyme (3). Therefore the cell population deficient in enzyme would probably lyse when exposed to an oxidant challenge without affecting the population of cells with a normal enzyme content (2). When there is unfavourable lyonization with the random inactivation of normal $\mathrm{X}$ chromosome, the population of G6PD deficient cells is much larger and the total red cell enzyme concentration will be similar to those in hemizygous males (2). This would result in a greater degree of haemolysis upon exposure to an oxidant challenge.

G6PD deficiency is significantly less frequent in females than males (5). Most clinicians believe that G6PD deficiency is exclusively a male disease. For this reason some female patients may go under diagnosed (5).

\section{References}

1. Mehta A, Mason PJ, Vulliamy TJ. Glucose-6-phosphate dehydrogenase deficiency. Baillieres Best Pract Res Clin Haematol, 2000 Mar; 13(1): 21-38.

2. Lim F, Vulliamy T, Abdalla SH. An Ashkenazi Jewish woman presenting with favism. J Clin Pathol, Mar 2005; 58(3): $317-9$

3. Beutler E, Yeh M, Fairbanks VF. The normal human female as a mosaic of $\mathrm{X}$-chromosome activity: studies using the gene for G6PD deficiency as a marker. Proc Natl Acad Sci USA, Jan 1962; 48(1): 9-16.

4. Jennifer E. Diagnosis and Management of G6PD Deficiency. Am Fam Physician, 2005 Oct 1; 72(7): 127782.

5. Albayrak C, Albayak B. Red cell G6PD deficiency in the northern region of Turkey - Is G6PD deficiency exclusively a male disease? Paediatric Haematol Oncol, 2014 Aug 12 